\title{
Enhancing the Professional Self-Concept of Nursing Students: A Qualitative Content Analysis
}

\author{
Yeowon Jeong ${ }^{1}$ \\ Dongguk University \\ Gyeongju-si, Republic of Korea
}

\begin{abstract}
This study aimed to identify nursing students' experiences with the interview as a strategy to improve professional self-concept, and determine whether the interview is an effective strategy to enhance it. Nursing students performed interview with a total of 36 healthcare professionals on a topic related to nursing and completed the openended questionnaire about their experience of interview. The openended questionnaire was analysed using qualitative content analysis. One main and three sub-themes within the interview were revealed: the interview is an opportunity for experience, understanding, and interaction. Based on the results, interview is a useful strategy for enhancing nursing students' professional self-concept.
\end{abstract}

Keywords: Professional self-concept; Interview; Communication; Nursing; Students.

\section{Introduction}

Given the current and ongoing predictions of nursing shortages worldwide, nursing turnover has gained much attention (Duffield et al., 2014). The loss of new graduate nurses is a negative factor that contributes to the continued worsening of nursing shortage. In the United States, over a quarter $(25.6 \%)$ of all new nurses left their first job within one year (National Health Care Retention \& RN Staffing Report, 2016), and more than one in three in Korea left (Jung et al., 2013). The new graduate transition, moving from a student role to that of a working registered nurse, can come as a shock due to an overload of new experiences and the demands of all their new responsibilities (Ankers, Barton, \& Parry, 2018; Cowin \& Hengstberger-Sims, 2006). New graduate nurses have difficulty adapting to clinical settings right after graduation which leads to nursing turnover; therefore, programs or strategies implemented at the

${ }^{1}$ Corresponding Author: Department of Nursing, College of Medicine, Dongguk University,

E-mail: ywjeong@dongguk.ac.kr 
academic level are needed to help them adjust in their first jobs. In this regard, few nursing researchers have specifically mentioned professional self-concept (Arthur, 1992; Kelly \& Courts, 2007; Shin, Choi \& Kim, 2016, Cao et al., 2015), particularly as a predictor of nursing turnover, retention or burnout. Positive professional self-concept can be interpreted as an index of nursing students' adjustment to professional roles (Arthur, 1992), which influences their desire to remain in nursing (Kelly \& Courts, 2007). Additionally, fostering a professional self-concept early in the learning process is essential for students when they are transitioning into the profession (Kelly \& Courts, 2007). The literature review demonstrates that it is important to understand the specific factors that are relevant to professional self-concept and the strategies that are effective in enhancing it.

The literature review was focused on the concept of professional self-concept and reviewed research from 1990, when professional self-concept emerged as a key concept for successful clinical adaptation of nurses after graduation (Arthur, 1995), until the present day. Subsequently, strategies for developing this concept emerged from the results of this review.

\subsection{Factors that influence the turnover of new graduate nurses in Korea} The factors that affect turnover of new graduate nurses can be divided into organizational and individual factors. Here, it was focused on individual factors related to 'transition shock' (Duchscher, 2009) that occurs in the process of moving from an academic environment to a clinical setting during their initial 14 months post-orientation.

Duchscher (2009) noted that expectations on relationships, roles, responsibilities, and knowledge required between academic and clinical settings are an apparent contrast, so that cause confusion, doubt, loss, and disorientation. New graduate nurses feel much anxiety and fear due to clinical incompetence, and have difficulty interacting with senior nurses or other professionals, especially, those who communicate with an oppressive hierarchical work (Duchscher, 2009). In Korea, it is also found in interpersonal stresses that include conflicts with other departments, such as physicians, pharmacists, and radiation workers (Suh \& Lee, 2013). This is due to the lack of understanding others' tasks as well as unskilled communication in conflict situations (Suh \& Lee, 2013).

Some new graduate nurses regret their career choice because of the public perception or attitude on nurses (Suh \& Lee, 2013). The thought of not being respected by patients, derived from the perception or attitude, negatively impacts professional self-concept (Hoeve, Jansen, \& Roodbol, 2014) and leads to conflicts with professional identity as a nurse (Hoeve et al., 2014; Kim \& Jeon, 2014).

Therefore, in order to reduce the turnover of new graduate nurses, efforts should be made to improve communication skills with other healthcare professionals from the initial nursing curriculum. Furthermore, it is necessary to 
consider understanding the work of other healthcare professionals, and their thought or image about nursing.

\subsection{Professional self-concept overview}

Professional self-concept, a specific domain of self-concept, is an attitude or feeling about oneself as a professional nurse (Arthur, 1992; Randle \& Arthur, 1997) that is based on the nature and value of nursing (Arthur, 1992; Arthur et al., 1999). The professional self-concept consists of three dimensions: (1) Professional practice - (a) Leadership, (b) Flexibility, and (c) Skill; (2) Satisfaction, and (3) Communication (Arthur, 1992; Arthur et al., 1999).

The professional self-concept of nurses is an important component of their professional and academic development (Arthur, 1995; Wang et al., 2019). A higher professional self-concept can help nurses use their learning experience optimally (Cowin \& Hengstberger-Sims, 2006; Wang et al., 2019) and deal effectively with the problems and pressures of professional practice (Arthur, 1992; Sohng \& Noh, 1996). Additionally, professional self-concept influences the retention and turnover of new graduate nurses (Kelly \& Courts, 2007; Randle \& Arthur, 2007).

Considering that the professional self-concept of new graduate nurses is lower than that of career nurses (Sohng \& Noh, 1996), its development needs to be cultivated in nursing schools by means of educational strategies. Some studies have shown that relevance of professional self-concept extends to professional identity, self-concept, and public image of nurses (Hoeve, Jansen, \& Roodbol 2014; Öhlén \& Segesten, 1998; Takase, Kershaw \& Burt, 2001).

\subsection{Professional identity}

Professional self-concept develops from experiences that promote a professional identity (Arthur, 1992; Hoeve et al., 2014). This paper's definition of professional identity adopts that of Fagermonen (1997), which gives the following definition: "Professional identity is defined as the values and beliefs held by a nurse that guides her/his thinking, actions and interactions with patients."

During nursing education, professional identity is developed through socialization by interaction among nursing students or healthcare professionals, including nurses (Öhlén et al., 1998; Fagermoen, 1996; Johnson et al., 2012), and is reflected in the professional self-concept (Hoeve et al., 2014; Arthur, 1995). A key factor for socialization process is communication (Johnson et al., 2012). Communication is also a third dimension of the professional self-concept (Arthur, 1995). Research has shown that difficulty communicating with those in other positions in clinical settings was a factor in nursing turnover (Duchscher, 2009), so strategies to hone communication skills and provide opportunities for interpersonal communication should be considered in the early stages of nursing education in order to focus on the socialization process. 
In addition to forming a positive professional identity, strategies that allow nursing students to share their experiences with practicing nurses and with other healthcare professionals should be implemented (Öhlén, 1998). Therefore, a nursing curriculum should provide opportunities for communication among nursing students and nurses or other healthcare professionals in addition to clinical training.

\subsection{Public image of nurses.}

The self-concept of nurses may be shaped by the public image of nurses (Hoeve et al., 2014; Fagermoen, 1997). The perceptions and images that their colleagues, patients, and other healthcare professionals have on nurses affect the professional identity of nurses. Additionally, nurses' feelings and experiences formed by interacting with other people around them can be influenced by professional self-concept (Öhlén, 1998, Fagermoen, 1997).

In this respect, a nursing curriculum should provide nursing students an opportunity to identify the public image of nurses held by people who have an impact on the students, such as friends and other healthcare professionals.

\subsection{Socialization}

Professional identity and self-concept are developed through the socialization process by interaction between nurses or nursing students with other healthcare professionals, and communication is a key factor for this (Hoeve et al., 2014; Johnson et al., 2012). Also, communication is the third dimension of the professional self-concept (Arthur, 1995). Research has shown that difficulty communicating among professions in clinical settings was one of the factors in nursing turnover (Duchscher, 2009). As mentioned above, communication is related to socialization of nursing students.

Therefore, strategies to promote communication skills and opportunities for interpersonal communication should be considered early in education, focusing on the socialization process.

\subsection{Strategies to develop and enhance the professional self-concept - Interview}

Strategies developing and enhancing the professional self-concept of first-year Korean nursing students in this study were selected based on a review of previous literature. Based on the literature review, factors that could develop and enhance the professional self-concept of first year Korean nursing students in this study were determined as follows: (1) Professional identity (2) Public image, and (3) Socialization. Strategies were selected considering the characteristics of each factor derived from literature review.

As a result, an interview was selected as a strategy to identify the public image of nurses and socialization, and share their thoughts on what nursing means 
among healthcare professionals, including nurses. The interview took the form of a formal meeting in which someone is asked questions about their thoughts, opinions, et cetera (Oxford dictionaries, 2017). An interview has been utilized in various fields, media, and even lectures in schools as a method to identify others' thoughts. In previous studies, the interview has been selected as an effective method of data collection in nursing studies (Musselwhite et al., 2007; Dilorio et al., 1994), however, there existed no studies utilizing the interview as a strategy related to the professional self-concept. In addition, a strategic approach to recognize and build up professional identity was adopted by asking students to discuss, 'Exploring my own meaning of nursing', and Team-based discussion was also adopted as a strategy for socialization. This study was focused on examining nursing students' perceptions and experiences on interview.

\section{Purpose}

This study aimed to identifying nursing students' subjective experiences with the interview, and to discuss its effectiveness as a strategy to influence professional self-concept.

\section{Research Design and methods}

This study used a qualitative content analysis to examine how nursing students experience interviews and the detailed research methods are as follows.

\section{1 Research participants}

This study used a convenience sample of 75 nursing students (66 female, 9 male) in a nursing department at a university in Gyeongju, Korea. These students were in the first year of a Bachelor of Science in Nursing (BSN) program. Students were divided into a total of twelve groups ( $6 \sim 7$ persons per group), and an interview was conducted two times over three weeks within one course during the semester.

\section{2 Data collection and Procedure}

A course was conducted over three weeks. In the first week, a brief overview of concepts, strategies, and research was presented in an orientation session. Then, students received an open-ended question: "What do you think about nursing? Please freely write down the meaning or values of nursing." And each group shared their thought and discussed what nursing is.

Interviews were conducted three times over three weeks with participants who were divided into groups (6 7 persons per group). Each group interviewed three persons related to them - two healthcare professionals and a friend as a non-healthcare professional. Twelve groups were interviewed a total of 36 individuals (7 doctors, 9 nurses, 6 pharmacists, 2 radiologists, and 12 friends). The outcome of each interview was considered and discussed in the second and third classes. After the three weeks, students were asked to complete an open- 
ended question: "Please freely write down things you felt in the process of interview." All data were collected after the course.

\subsection{Ethical consideration}

Prior to starting the course, nurses were apprised of the purpose, methods, anticipated benefits, and potential risks of this study. The author noted that participation was voluntary and that there would be no disadvantage if they decided not to participate. After obtaining informed consent, the open-ended questionnaire was then provided to nursing students who were willing to participate in the study. All participants completed the open-ended questionnaire anonymously and voluntarily.

\subsection{Data Analysis}

The qualitative data of the open-ended questionnaire were analyzed using the three-step qualitative content analysis described by Graneheim and Lundman (2004): (1) coding the meaningful words or sentences through reading the materials repeatedly, (2) organizing the meaningful words or sentences and creating categories, and (3) generating themes from categories.

\section{Results}

The qualitative data was analyzed by content analysis. The results demonstrated that one main theme and three sub-themes emerged (Figure 1). The main theme was that "interview is an opportunity." and the three sub-themes were: (1) experience, (2) understanding, and (3) interaction. Table 1 shows detailed meaning units, main theme, and sub-themes. It also described students' thoughts or attitude changes regarding nursing as expressed in the reflective journals in relation to each sub-theme.

\section{1 Interview is an opportunity for experience.}

Students reported that the interview was an opportunity to experience indirectly what the life of nurses in a clinical area is like. An interview afforded students the chance to hear about "vivid experience (p1 \& p2), difficulties (p21), precise and detailed information (p3 \& p40 \& p46), and advice" (p48) related to nursing and being better nurses. These experiences led students to draw up a blueprint using positive opinion of themselves as prospective nursing school graduates. However, the "vivid experience" that nurses' work is hard led some students $(\mathrm{N}=3)$ to be concerned about the career, prompting them to question "Can I do well?" (p50). Several students expressed that the experience of nurses working in various fields had expanded the limited view of students who considered hospitals the only nursing area. Before the interview, some students felt a vague anxiety about nursing work and a lack of confidence in being able to perform the job; however, through listening to the nurses' experiences and advice during the interview, these feeling turned into a bit of anticipation. Additionally, students experienced improved "self-esteem" (p54) through identifying a positive 
attitude or image of nurses that other healthcare professional or friends expressed during the interview.

Table 1. Meaning Units, Condensed Meaning Units, Sub Theme and Themes from Content Analysis of Interview

Meaning Units
(1) I learned a lot by listening directly
to nurses' experiences in the
nursing field.
(2) It was helpful to receive practical
knowledge and experience by
directly interacting with nurses
rather than just theoretical
learning.


their thoughts or opinions related

nurses

to nursing.

(4) It was a good chance to properly understand other people's thoughts and the changes in their perceptions regarding nurses.

(5) I was satisfied to hear in detail the thoughts of others and gained confidence.

(6) I did not have many chances to talk to the people around me, but it was a pleasure to have time to talk with them.

(7) I gained confidence by knowing that other healthcare professionals working with nurses have a positive attitude (image) about nurses.

(8) It was useful to know how a friend studying another major saw and thought about nurses.

\section{2. Interview is an opportunity of understanding.}

The students reported that the interview was an opportunity to be able to understand nursing and nurses seriously. This conclusion was supported by one of the students stating that $\mathrm{s} /$ he gained "a deeper understanding of nursing and nurses as a profession through the interview" (p40). Students expressed that they had chances to think deeply for the first time about what nursing is and the qualifications required for the career that they planned to undertake in the future. In addition, students stated that professional skill and knowledge as well as a sense of responsibility for patients' well-being were indispensable as nurses' qualifications. These understanding expanded the scope of students' viewpoints and led to "the detailed planning about what was needed to prepare and develop during the time in university to become a better nurse" (p59).

\section{3. Interview is an opportunity of interaction.}

Students stated that the interview provided an opportunity to interact with students and other people including healthcare professionals, friends, family, and so on. Students indicated that all the processes represented by the interview, such as communicating, learning about others' thoughts on nursing, and sharing their view on nursing with others, were essential to understanding others, each job, and to bridge the gap of each thought. One student reported that talking about nursing with other healthcare professionals was the chance to "throw out a prejudice toward others' job she/he had before" (p16). Furthermore, these thoughts were connected to the clinical area, in which students felt that a relationship of mutual cooperation, (rather than assistance) between other 
healthcare professionals and nurses is a critical element for patients' well-being. In addition, students noted that clinical nurses need to make an effort to communicate closely with patients. They realized the importance of interaction with others through the interview activity.

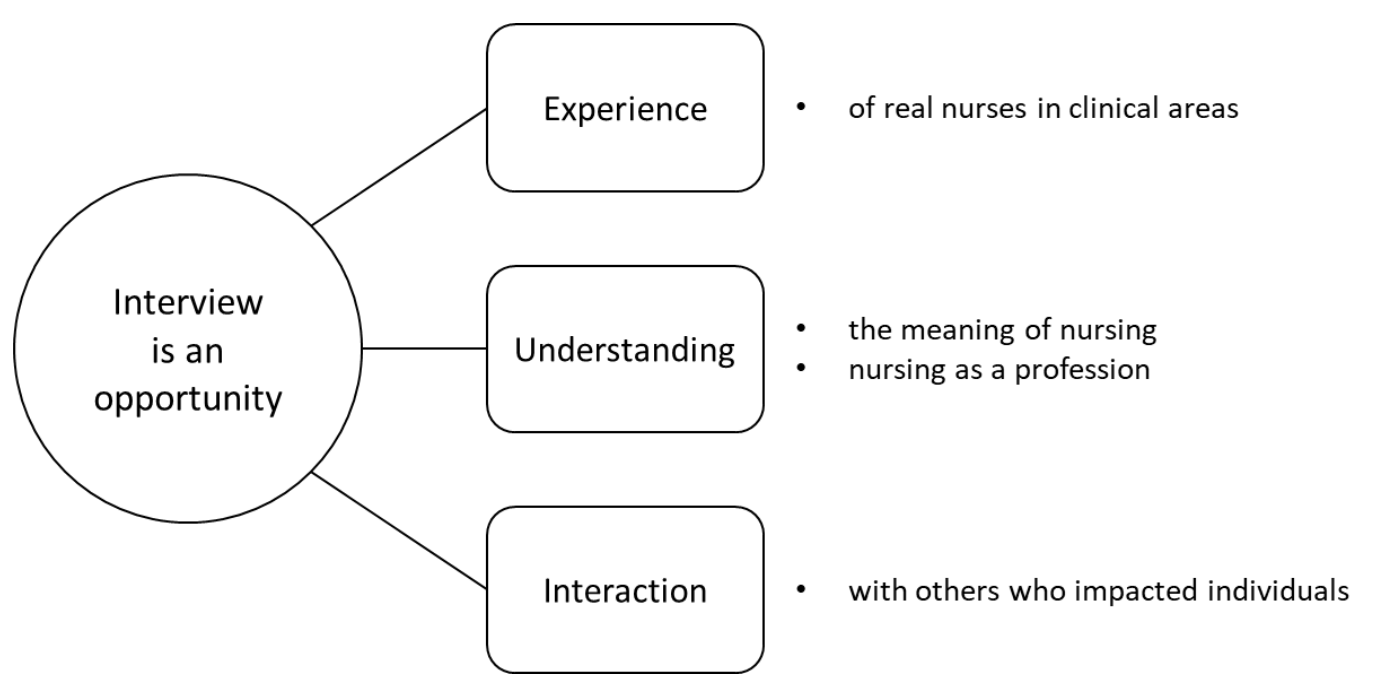

Figure 1. Main themes and sub-themes of the interview

\section{Discussion}

In this study, students expressed that they gained confidence in the nursing profession by means of identifying others' thoughts, perceptions, and positive images of nursing and nurses through an interview. This implies that the image held by other people toward nurses affects the students' attitude toward nursing. As professional self-concept is an attitude or feeling about oneself as a professional nurse (Arthur, 1992; Randle \& Arthur, 2007), which is influenced by the public's image of nurses (Hoeve et al., 2014; Randle \& Arthur, 2007), , it is expected that improved confidence has a positive influence on professional selfconcept. An interview is an appropriate method for identifying others' thoughts as well as for ascertaining public opinion of nurses, making it a useful strategy to improve professional self-concept.

Interview yielded concrete, practical information (Zanting, Verloop, \& Vermunt, 2003). Through an interview, students within the current study obtained realistic experiences, information, knowledge, and advice that enabled them to find their own meaning in answer to the specific question, "What do you think about nursing and the nursing profession?" As a result, students reported that they were able to understand the fundamentals of nursing and identify their own meaning of nursing and the nursing profession. It appears that an interview is helpful to students in the process of finding their own professional identity, as reflected in the professional self-concept (Hoeve et al., 2014; Arthur, 1995).

Professional self-concept is positively correlated with understanding based on communication with various healthcare professionals (Kyung, 2011). In this study, a course that included interview activity and team discussion provided 
nursing students with continuous and repetitive communication training as well as opportunities to communicate with a variety of people (including professionals, colleagues, friends, and family) about a specific theme related to nursing. After the course, students stated that they expanded their understanding of other healthcare professionals' jobs through the interview process, which indicated that the interview was an effective strategy. Furthermore, some studies have shown that team-based discussion improved students' communication skills (Bick et al., 2006; Craft et al., 2017). Communication is a factor in the socialization process (Hart, Miller, \& Johnson, 2003), and inter-professional socialization and interaction have a significant impact on patient outcomes in the healthcare setting (LaRochelle \& Karpinski, 2016; Martin et al., 2010). Accordingly, experience and training in communicating with various people, including healthcare professionals, should be supplied early in a nursing education program.

\section{Conclusions}

Professional self-concept is one of the important components of being a professional nurse. From early in the nursing school curriculum, different efforts, programs, and strategies are required to develop and enhance professional self-concept.

The interview is a widely used method in various fields. The result of this study showed that the interview was useful as a strategy for nursing students to achieve exposure to nursing-related experiences, practice effective communication, and enhance professional self-concept. More specifically, it allows students to expand their experience of nursing, to explore the identity of nursing individually, and to increase their awareness of the necessity to understand and collaborate with other healthcare professionals in practice. In the process of conducting the interview, it is expected that students will learn, practice, and reinforce interaction, communication, and cooperation with other members of the society.

\section{Limitations and Recommendations}

There was a limitation in this study. The sample for this study was a convenience sample from a single university; thus, the results may not apply to other fields. Despite this limitation, it is expected that the result of the study can be used as basic data for research related to the strategies for professional selfconcept. Future studies are needed to develop a program to improve professional self-concept that applies various strategies, including the interview method, and quantitative research should examine its effect using tools to evaluate professional self-concept.

\section{Acknowledgment}

I sincerely appreciate all students who participated in this study and who worked together in the course, sharing their experiences. 


\section{Conflict of interest}

The authors report no actual or potential conflicts of interest.

\section{References}

Ankers, M. D., Barton, C. A., \& Parry, Y. K. (2018). A phenomenological exploration of graduate nurse transition to professional practice within a transition to practice program. Collegian, 25(3), 319-325. https://doi.org/10.1016/j.colegn.2017.09.002

Arthur, D. (1992). Measuring the professional self-concept of nurses: a critical review. Journal of Advanced Nursing, 17(6), 712-719. https://doi.org/10.1111/j.1365-2648.1992.tb01969.x

Arthur, D. (1995). Measurement of the professional self-concept of nurses: developing a measurement instrument. Nurse Education Today, 15(5), 328-335. https://doi.org/10.1016/S0260-6917(95)80004-2

Arthur, D., Pang, S., Wong, T., Alexander, M., Drury, J., Eastwood, H., ... Noh, C. (1999). Caring attributes, professional self concept and technological influences in a sample of Registered Nurses in eleven countries. International Journal of Nursing Studies, 36(5), 387-396. https://doi.org/10.1016/S0020-7489(99)00035-8

Bick, R. J., Oakes, J. L., Actor, J. K., Cleary, L. J., Felleman, D. J., Ownby, A. R., . . Seifert, W. (2009). Interactive teaching: problem solving and integration of basic science concepts into clinical scenarios using team-based learning. International Association of Medical Sciences Educators Journal, 19(1), 26-34.

Cao, X., Chen, L., Tian, L., Diao, Y., \& Hu, X. (2015). Effect of professional self- concept on burnout among community health nurses in Chengdu, China: the mediator role of organizational commitment. Journal of clinical nursing, 24(19-20), 29072915. https://doi.org/10.1111/jocn.12915

Cowin, L. S., \& Hengstberger-Sims, C. (2006). New graduate nurse self-concept and retention: A longitudinal survey. International Journal of Nursing Studies, 43(1), 59-70. https://doi.org/10.1016/j.ijnurstu.2005.03.004

Craft, J., Christensen, M., Bakon, S., \& Wirihana, L. (2017). Advancing student nurse knowledge of the biomedical sciences: A mixed methods study. Nurse Education Today, 48, 114-119. https://doi.org/10.1016/j.nedt.2016.10.003

Dilorio, C., Hockenberry-Eaton, M., Maibach, E., \& Rivero, T. (1994). Focus groups: an interview method for nursing research. The Journal of Neuroscience Nursing: Journal of the American Association of Neuroscience Nurses, 26(3), 175-180.

Duchscher, J. E. B. (2009). Transition shock: the initial stage of role adaptation for newly graduated Registered Nurses. Journal of Advanced Nursing, 65(5), 1103-1113. https://doi.org/10.1111/j.1365-2648.2008.04898.x

Duffield, C. M., Roche, M. A., Homer, C., Buchan, J., \& Dimitrelis, S. (2014). A comparative review of nurse turnover rates and costs across countries. Journal of Advanced Nursing, 70(12), 2703-2712. https://doi.org/10.1111/jan.12483

Fagermoen, M. S. (1997). Professional identity: values embedded in meaningful nursing practice. Journal of Advanced Nursing, 25(3), 434-441. https://doi.org/10.1046/j.1365-2648.1997.1997025434.x

Graneheim, U. H., \& Lundman, B. (2004). Qualitative content analysis in nursing research: concepts, procedures and measures to achieve trustworthiness. Nurse Education Today, 24(2), 105-112. https://doi.org/10.1016/j.nedt.2003.10.001

Hart, Z. P., Miller, V. D., \& Johnson, J. R. (2003). Socialization, resocialization, and communication relationships in the context of an organizational change. 
Communication

Studies,

$54(4)$

483-495. https://doi.org/10.1080/10510970309363305

Hoeve, Y. t., Jansen, G., \& Roodbol, P. (2014). The nursing profession: public image, self-concept and professional identity. A discussion paper. Journal of Advanced Nursing, 70(2), 295-309. https://doi.org/10.1111/jan.12177

Johnson, M., Cowin, L. S., Wilson, I., \& Young, H. (2012). Professional identity and nursing: contemporary theoretical developments and future research challenges. International Nursing Review, 59(4), 562-569.

https://doi.org/10.1111/j.1466-7657.2012.01013.x

Jung, E. J., Chae, G. S., Noh, W. J., Park, M. M., Cho, E. Y., \& Kim, H. J. (2013). Hospital Nursing Social Report. Survey on the status of hospital nursing staff placement. Retrieved from Seoul

Kelly, S., \& Courts, N. (2007). The professional self-concept of new graduate nurses. $\begin{array}{llll}\text { Nurse Education in } & \text { 332-337. }\end{array}$ https:// doi.org/10.1016/j.nepr.2006.10.004

Kim, S. A., \& Jeon, H. W. (2014). Experience of turnover in new nurses. Journal of Korean Public Health Nursing, 28(3), 644-657. https:/ / doi.org/10.4040/jkan.2008.38.2.248

Kyung Sook, K. (2011). A study on professional self concept perceived by nursing student. Journal of the Korean Data Analysis Society, 13(4), 1991-2001. Retrieved from http:/ / www.riss.kr/link?id=A101600856

LaRochelle, J. M., \& Karpinski, A. C. (2016). Racial differences in communication apprehension and inter-professional socialization in fourth-year doctor of pharmacy students. American Journal of Pharmaceutical Education, 80(1), 8. https://doi.org/10.5688/ajpe8018

Martin, J., Ummenhofer, W., Manser, T., \& Spirig, R. (2010). Interprofessional collaboration among nurses and physicians: making a difference in patient outcome. Swiss Medical Weekly, 140, w13062. https://doi.org/10.4414/smw.2010.13062

Musselwhite, K., Cuff, L., McGregor, L., \& King, K. M. (2007). The telephone interview is an effective method of data collection in clinical nursing research: A discussion paper. International Journal of Nursing Studies, 44(6), 1064-1070. https://doi.org/10.1016/j.ijnurstu.2006.05.014

NSI. (2016). 2016 National Health Care Retention \& RN Staffing Report. Retrieved 2016 Dec 22 from NSI Nursing Solutions, Inc. http:/ / www.nsinursingsolutions.com/Files/assets/library/retentioninstitute/NationalHealthcareRNRetentionReport2016.pdf

Öhlén, J., \& Segesten, K. (1998). The professional identity of the nurse: concept analysis and development. Journal of Advanced Nursing, 28(4), 720-727. https://doi.org/10.1046/j.1365-2648.1998.00704.x

Oxford dictionaries online. (2017). $\quad$ Retrieved from https://www.lexico.com/en/definition/lnterview

Randle, J., \& Arthur, D. (2007). The professional self concept of nurses: a review of the literature from 1992-2006. Australian Journal of Advanced Nursing, 24(3), 60. Availability:

<https:/ / search.informit.com.au/documentSummary;dn=403000570176504;res= IELAPA $>$.

Shin, S. H., Choi, H. R., \& Kim, S. M. (2016). Impact on the degree of labor turnover of professional self-concept and emotional labor: A case of female children's hospital nurses. The Journal of the Korea Contents Association, 16(5), 375-383. https://doi.org/10.5392/JKCA.2016.16.05.375 
Sohng, K. Y., \& Noh, C. H. (1996). An analytic study of the professional self-concept of hospital nurses in Korea. Journal of Korean Academy of Nursing, 26(1), 94-106. https://doi.org/10.4040/jnas.1996.26.1.94

Suh, Y., \& Lee, K. (2013). Lived experiences of new graduate nurses. Journal of Korean Academy of Nursing Administration, 19(2), 227-238. https://doi.org10.11111/jkana.2013.19.2.227

Takase, M., Kershaw, E., \& Burt, L. (2001). Nurse-environment misfit and nursing practice. Journal of Advanced Nursing, 35(6), 819-826. https://doi.org/10.1046/j.1365-2648.2001.01933.x

Wang, M., Guan, H., Li, Y., Xing, C., \& Rui, B. (2019). Academic burnout and professional self-concept of nursing students: A cross-sectional study. Nurse education today, 77, 27-31. https://doi.org/10.1016/j.nedt.2019.03.004

Zanting, A., Verloop, N., \& Vermunt, J. D. (2003). Using interviews and concept maps to access mentor teachers' practical knowledge. Higher Education, 46(2), 195-214. https://doi.org/10.1023/A:102471981665 